\title{
Determination of the Output Impedance of the Injecting Current Source for Electrical Impedance Tomography
}

\author{
G.K. Aleksanyan, I.D. Shcherbakov, A.I. Kucher and N.I. Gorbatenko \\ Department of Information and Measurement Systems and Technologies, \\ Platov South Russia State Polytechnic University (NPI), Novocherkassk, Russia
}

\begin{abstract}
The output impedance is one of the most important parameters of the current source in the composition of the information-measuring system of electrical impedance tomography on which the metrological characteristics of the entire system depend. In this study, a setup was developed for conducting studies of the output impedance of the current source in a given amplitude range and frequency of the output current. Studies of the output impedance of the current source were carried out as a result, a characteristic was obtained, the use of which will further help to improve the design of the device for electrical impedance tomography.
\end{abstract}

$\underline{\text { Key words: Electrical impedance tomography, current source, impedance, characteristic, tomography, electrical }}$

\section{INTRODUCTION}

The study describes the studies output parameters of the current source Electrical Impedance Tomography (EIT) device component (Aleksanyan et al., 2016). The current source is the most important component of the equipment for EIT which determines the metrological characteristics of the entire measuring path (Aleksanyan et al., 2017a, b; Bertemes-Filho et al., 2000).

\section{MATERIALS AND METHODS}

The current source being developed should meet the following requirements:

- Voltage management

- Current amplitude through the load: $5 \mathrm{~mA}$ (Kulikov, 2010)

- Current amplitude error-no more than $1.5 \%$

- Maximum current frequency $-100 \mathrm{kHz}$

- Grounded load resistance $\mathrm{R}_{\mathrm{H}}-50 \quad \Omega-2 \quad \mathrm{k} \Omega$ (Aleksanyan et al., 2017a, b)

The use of an inverting or electromechanical amplifiers with a load in the feedback circuit is impossible due to the fact that a constant potential cannot be applied to either end of the load, since in this case, one output or the inverting input of the op-amp will be shorted (Titze and Schenk, 1982). These requirements are satisfied by the CS scheme with automatic measurement and regulation of the current in the load (Brazovskiy, 2015). The functional diagram of the developed CS as part of a data collection and transmission device for EIT is presented in Fig. 1.

The output current is measured by the voltage drop $\mathrm{Uw}$ on the resistor $\mathrm{R}_{\mathrm{w}}$. For this, a differential amplifier at the op-amp 2 is used. If the gain factor is $\mathrm{K}_{\mathrm{U}}=\mathrm{R}_{\mathrm{d}} / \mathrm{R}_{\mathrm{b}}\left(\mathrm{R}_{\mathrm{a}}=\mathrm{R}_{1}=\mathrm{R}_{3} ; \mathrm{R}_{\mathrm{b}}=\mathrm{R}_{2}=\mathrm{R}_{4}\right)$ differential amplifier (Chizhma, 2012) on OP2 is equal to 1 , then, the output voltage of the operational amplifier OP1 is set such that the voltage drop $U_{w}$ on the resistor $R_{w}$ is equal to the input voltage $\mathrm{U}_{\text {out }}$. Increasing the gain $\mathrm{K}_{\mathrm{U}}$ allows proportionately reduce the nominal resistance of the resistor $\mathrm{R}_{\mathrm{W}}$. Voltage repeaters at $\mathrm{OP} 3$ and $\mathrm{OP} 4$ increase the input impedance of the differential amplifier at OP2. The circuit diagram of the developed injecting current source CS is presented in Fig. 2.

Form and frequency $f_{I}$ current $I$ at the OUT pin of the current source correspond to the shape and frequency $f_{m}$ of the control signal $\mathrm{U}_{\mathrm{m}}$ at the $\mathbb{N}$ terminal of the current source. Amplitude $\mathrm{I}_{\mathrm{m}}$ of at the CS output is proportional to the amplitude $\mathrm{U}_{\mathrm{m}}$ control voltage at terminal $\mathrm{IN}$ and CS is set Resistor $R_{2}$. The current source starts operation immediately after the appearance of power on the connector 3. Pin CS IN is connected to the common point via. a Resistor $R_{1}$ to prevent the appearance of $I$ on pin OUT CS due to the impact of the induced voltage on the output IN CS. Used instrumental amplifier AD 8429 ARZ produced by analog devices with a disconnected resistor that sets the gain which allows for the gain of the instrumentation amplifier equal to 1 .

Corresponding Author: G.K. Aleksanyan, Department of Information and Measurement Systems and Technologies, Platov South Russia State Polytechnic University (NPI), Novocherkassk, Russia 


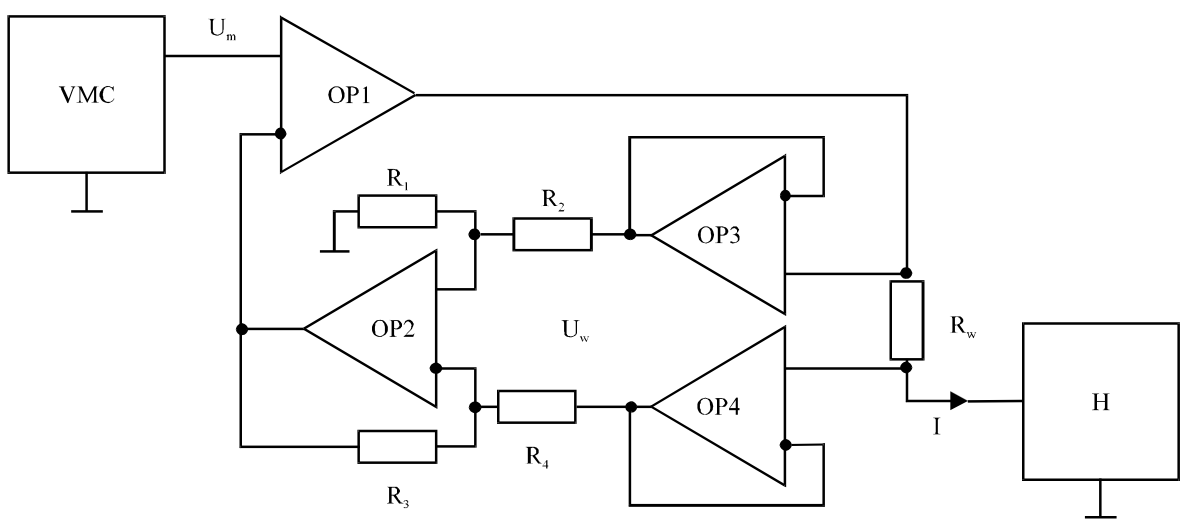

Fig. 1: Functional block diagram of current source of data acquisition and transmission EIT device
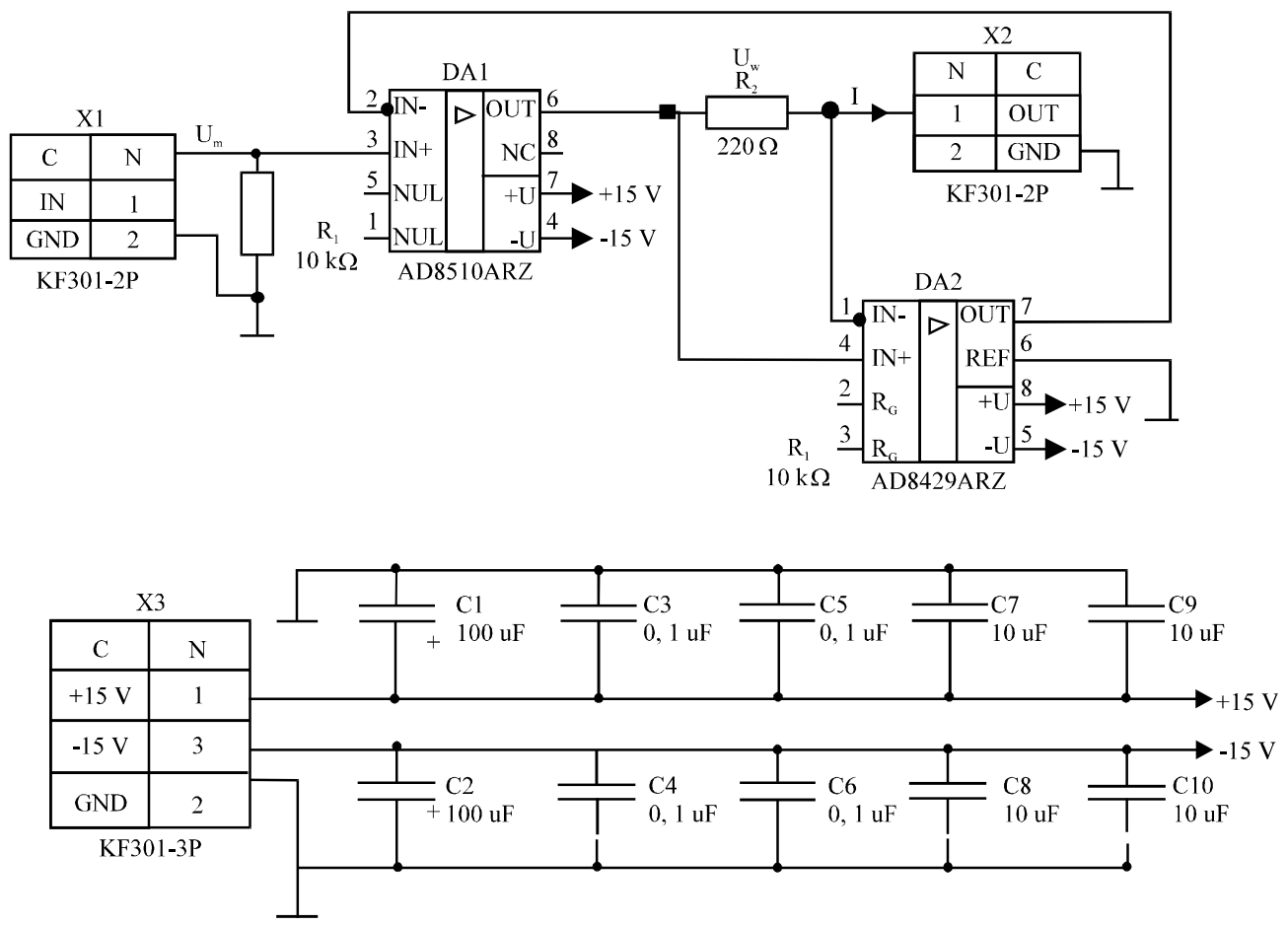

Fig. 2: Circuit diagram of current source of data acquisition and transmission EIT device

The CS PCB was developed in CAD system. The size of the board is $33.3 \times 23.3 \mathrm{~mm}$. The printed circuit board, assembly drawing and the appearance of the assembled source of the injecting current CS are shown in Fig. 3.

One of the most important parameters of the current source which determines its main characteristics is its output impedance $\mathrm{R}_{\text {out }}$ (Chizhma, 2012). As you know, the ideal current source has an infinitely large output impedance $\mathrm{R}_{\text {out. }}$. The real current source has a finite resistance $\mathrm{R}_{\text {out }}$ connected in parallel to the load resistance $R_{n}$ (Fig. 4). Due to the fact that $R_{\text {out }}$ is finite, current $I_{\text {int }}$ will flow through it. Thus, the total current $I_{n}$ through the load $R_{n}$ will be less then output current $I$ of current source on the amount of current $\mathrm{I}_{\text {int }}$. It's obvious that:

$$
\frac{I_{\text {in }}}{I_{H}}=\frac{R_{H}}{R_{\text {out }}}
$$

Thus, in order to influence the output impedance $\mathrm{R}_{0}$ on the current $I_{n}$ through the load $R_{n}$ did not exceed $1 \%$, the value of $R_{\text {out }}$ must satisfy the condition $R_{\text {out }} \geq 100$ $R_{n \max }$. The value of $R_{\text {max }}$ for the developed circuit is determined by the value of the current-setting resistance $\mathrm{R}_{\mathrm{W}}$ and the maximum resistance which output $\mathrm{OP} 1$ can be 
(a)

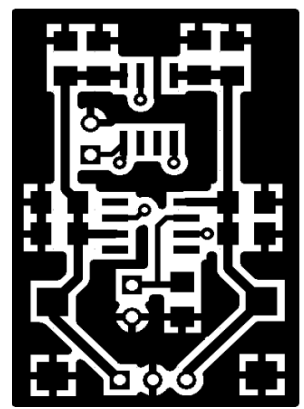

(b)

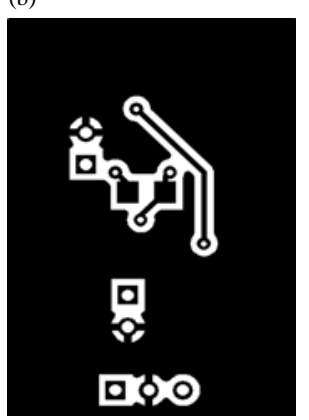

(c)

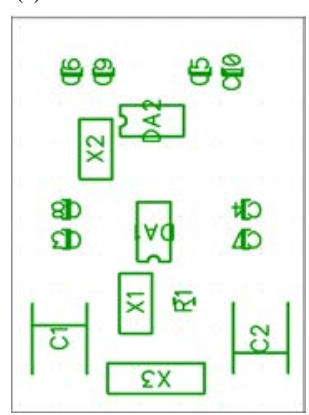

(d)

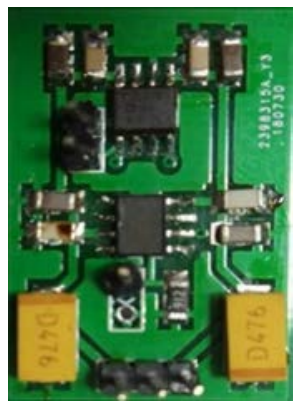

Fig. 3: a) Upper; b) Lower; c) Layers of a printed circuit board, assembly drawing and d) Appearance of current source for a data acquisition and transmission device for EIT

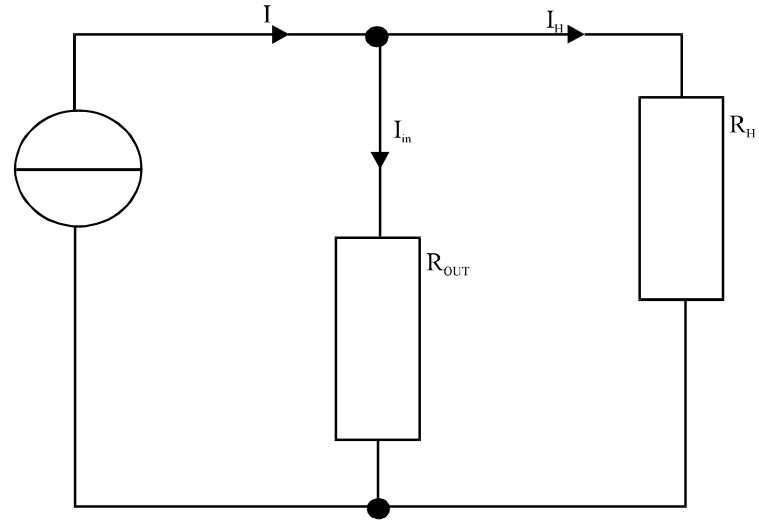

Fig. 4: The equivalent current source circuit with the output resistance

loaded by. For op amp AD 8510ARZ with supply voltage $\mathrm{U}= \pm 15 \mathrm{~V}$ maximum output voltage is not $< \pm 14 \mathrm{~V}$ (Brazovsky et al., 2015). In order to provide the output current of op-amp at least $\mathrm{I}_{\mathrm{DU}}= \pm 5 \mathrm{~mA}$ when the output voltage of $\pm 14 \mathrm{~V}$ resistance value $R_{\text {VMA }}$ applied to the op-amp output should not exceed 2,600 $\Omega$. Since, $\mathrm{R}_{\mathrm{VMA}}=$ $R_{W}+R_{n}+R_{K}$ (where, $R_{K}$ is the resistance of the current injection channel which is determined by the resistance of the multiplexers). For the DG 406 multiplexers used, the open channel impedance does not exceed $100 \Omega$ and the typical value is $50 \Omega$. Thus, $\mathrm{R}_{\max }=2180 \Omega$ which satisfies the requirements.

It is impossible to measure the output Resistance $\mathrm{R}_{\text {out }}$ in a straightforward way. But there are indirect ways to measure $\mathrm{R}_{\text {out }}$. Knowing the specified level of current $\mathrm{I}$ as well as the value of current $I_{n}$ through the load resistance $\mathrm{R}_{\mathrm{n}}$ for the maximum and minimum value of the load resistance $R_{n}$ you can calculate the value of the output resistance CS $\mathrm{R}_{\text {out }}$ using the equation:

$$
\mathrm{R}_{\text {out }}=\frac{\mathrm{I}_{\mathrm{H} 2} \cdot \mathrm{R}_{\mathrm{H} 2}-\mathrm{I}_{\mathrm{H} 1} \cdot \mathrm{R}_{\mathrm{H} 1}}{\mathrm{I}_{\mathrm{H} 2}-\mathrm{I}_{\mathrm{H} 1}}
$$

Table 1: Main alternating current measurement characteristics of the AKIP-2101 voltmeter

\begin{tabular}{ll}
\hline Parameters & Values \\
\hline AC current limits & $20 \mathrm{~mA} / 200 \mathrm{~mA} / 2 \mathrm{~A} / 10 \mathrm{~A}$ \\
Resolution & $100 \mathrm{nA} / 1 \mu \mathrm{A} / 10 \mu \mathrm{A} / 100 \mu \mathrm{A}$ \\
Frequent range & $20 \mathrm{~Hz}, \ldots, 100 \mathrm{kHz}$ \\
Measurement error & $\pm(0.5, \ldots, 2.5 \%)$ \\
\hline
\end{tabular}

where, $I_{H 1}$ the amplitude of the current through $R_{n}$ when $R_{n}=R_{n 1}$, $I_{H 2}$ the amplitude of the current through $R_{n}$ when $R_{n}=R_{n 2}$.

For the experimental evaluation of the output resistance $R_{\text {out }}$ of CS, we measure the amplitude of the current $I_{n}$ through $s$ load resistance $R_{n}$ at maximum and minimum value of load resistance $R_{n}$. As the load $R_{n}$ resistance is used with a nominal value of $R_{n 1}=52 \Omega$ and $\mathrm{R}_{\mathrm{n} 2}=2155 \Omega$. The experiment is performed for control voltage frequencies $\mathrm{f}_{\text {cont }}(10-100 \mathrm{kHz})$ and amplitude $I_{m}=5 \mathrm{~mA}$. The number of repeated experiments 11. To measure the amplitude of current $I_{n}$, a universal AKIP-2101 voltmeter is used (Anonymous, 2014). The main characteristics of $\mathrm{AC}$ voltage measurement by the AKIP-2101 voltmeter are summarized in Table 1.

The AKIP-2101 voltmeter allows you to measure the current $\mathrm{I}_{\text {RMS }}$ value (Anonymous, 2014) of the current, taking into account the waveform and distortion (True RMS). The calculation of the amplitude $\mathrm{I}_{\mathrm{m}}$ value is made according to the equation:

$$
\mathrm{I}_{\mathrm{m}}=\mathrm{I}_{\mathrm{RMS}} \cdot \sqrt{2}
$$

where, $I_{m}$ the amplitude of the alternating current $I_{R M S}$ is the effective value of alternating current. Togenerate the control signal $U_{\text {cont }}$ a special form generator AKIP$3409 / 5$ is used (Anonymous, 2014). The main characteristics of the generator are summarized in Table 2 . The scheme of the experimental stand is shown in Fig. 5 and 6. 


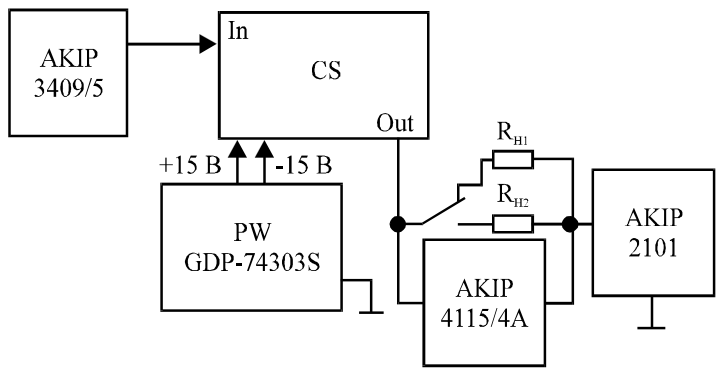

Fig. 5: The block diagram of the experimental stand for the study of current source

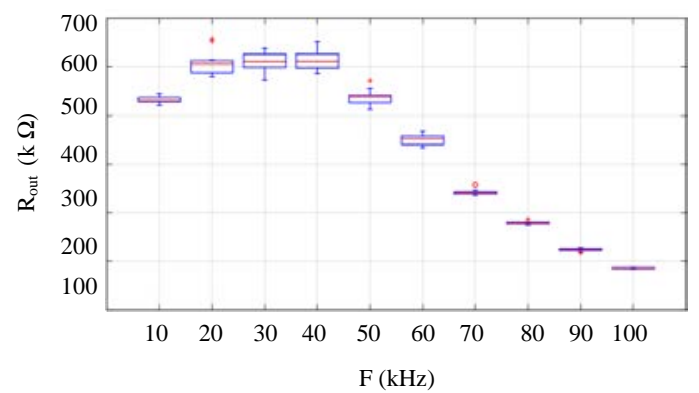

Fig. 6: Output resistance evaluation results

\begin{tabular}{ll} 
Table 2: The main characteristics of the generator AKIP-3409/5 \\
\hline Parameters & Values \\
Frequency range (sine) & $1 \mu \mathrm{Hz}-50 \mathrm{MHz}$ \\
Frequency resolution & $1 \mu \mathrm{Hz}$ \\
Bit depth of DAC & $14 \mathrm{bits}$ \\
DAC sampling rate & $125 \mathrm{MHz}$ \\
Level setting error at $1 \mathrm{kHz}$ & $\pm(0.01 \times \mathrm{A}+2 \mathrm{mV})$ with $\mathrm{A}<1 \mathrm{~V}$ \\
& $\pm(0.01 \times \mathrm{A}+10 \mathrm{mV})$ with $\mathrm{A}=1 \mathrm{~V}$ \\
Output level & $2 \mathrm{mVp}-\mathrm{p}-10 \mathrm{Vp}-\mathrm{p}$ \\
\hline
\end{tabular}

\section{RESULTS AND DISCUSSION}

The results of experimental studies of the current source are shown in Fig. 6. As can be seen from Fig. 6 in the frequency range $f_{I}=10, \ldots, 100 \mathrm{kHz}$ with current amplitude $\mathrm{I}_{\mathrm{m}}=5 \mathrm{~mA}$, the output impedance $\mathrm{R}_{\text {out }}$ of CS is in the range from $615-186 \mathrm{k} \Omega$. The maximum error for determining the output resistance $\mathrm{R}_{\text {out }} \mathrm{CS}$ is $8 \%$ at a frequency of $20 \mathrm{kHz}$ the minimum $-1 \%$ at a frequency of $100 \mathrm{kHz}$. Thus, the developed CS allows to provide a current I with amplitude $I_{m}=5 \mathrm{~mA}$ and frequency $\mathrm{f}_{\mathrm{I}}=10, \ldots, 100 \mathrm{kHz}$ through the load $\mathrm{R}_{\mathrm{n}}$ in the range from $50 \Omega-2 \mathrm{k} \Omega$ with an error of not more than $1.5 \%$.

\section{CONCLUSION}

The output impedance is one of the most important parameters of the current source used in the information-measuring system of electrical impedance tomography on which the metrological characteristics of the entire system depend. In this study, a setup was developed for conducting studies of the output impedance of the current source in a given amplitude range and frequency of the output current. Studies of the output impedance of the current source were carried out as a result, a characteristic was obtained, the use of which will further help to improve the design of the device for electrical impedance tomography.

\section{ACKNOWLEDGEMENTS}

The research is performed within the grant of President of Russian Federation for state support of young Russian scientists MK-196.2017.8 "Development of theoretical foundations and algorithms for multi-view systems are three-dimensional electrical impedance tomography for non-invasive medical imaging".

\section{REFERENCES}

Aleksanyan, G.K., I.D. Shcherbakov and A.I. Kucher, 2017a. Feature research of using current source in 2-dimensional and 3-dimensional multifrequency electrical impedance tomography devices. J. Eng. Appl. Sci., 12: 587-592.

Aleksanyan, G.K., I.D. Shcherbakov, A.I. Kucher and V.V. Demyanov, 2017b. Experimental research the human body impedance in the chest area depending the frequency of the injected current. J. Eng. Appl. Sci., 12: 2129-2137.

Aleksanyan, G.K., N.I. Gorbatenko, V.V. Grechikhin, T.N. Phong and T.D. Lam, 2016. Application of natural and model experiment methodology in two-dimensional electrical impedance tomography. ARPN. J. Eng. Appl. Sci., 11: 5871-5875.

Anonymous, 2014. Precision, very low noise, low input bias current, JFET operational amplifiers AD8510/AD8512/AD8513. Analog Devices, Norwood, Massachusetts, USA

Bertemes-Filho, P., B.H. Brown and A.J. Wilson, 2000. A comparison of the modified mirror type circuits. Physiol. Meas., 21: 1-6.

Brazovskiy, K.S., 2015. [Methods and technical means for assessing the functional state of the human brain based on electrical measurements]. MSc Thesis, Tomsk Polytechnic University, Tomsk, Russia. (In Russian). 
Brazovsky, K.S., Y.S. Pecker and A.I. Soldatov, 2015. Investigation of injecting current sources for electrical impedance tomography. Med. Equip., 16: 18-21.

Chizhma, S.N., 2012. Electronics and Microcircuitry: Studies. Federal State Budget Educational Establishmen, Moscow, Russian, Pages: 359.
Kulikov, G.B., 2010. Life Safety. Moscow State University of Printing Arts, Moscow, Russia, Pages: 408.

Titze, U. and K. Schenk, 1982. Semiconductor Circuit Design: Reference Guide. Mir Publisher, Moscow, Russia, Pages: 512. 